\section{Calcar-replacing Total Hip Replacement for A Giant Cell Tumor of the Proximal Femur: A Case Report and A Review of Literature}

\section{Juan Paulo Panti*, Cesar Dimayuga and Peter Bernardo}

Department of Orthopedic Surgery, University of the Philippines Philippine General Hospital, Manila, Philippines

\begin{abstract}
Giant Cell Tumor of the bone (GCTb) is a relatively benign but locally aggressive tumor, capable of producing debilitating lytic bone lesions with a rare likelihood of producing lung metastases. The proximal femur is an uncommon location for its occurrence, with more than $50 \%$ of these epi-metaphyseal lesions occurring around the knee joint. The reported incidence of GCTb in the proximal femur is only reported to be around $3-4 \%$. However, selecting the appropriate treatment is challenging due to the proximity with the hip joint, and the risk of damaging the insertion of several essential hip muscles. Joint-salvaging surgery primarily involves extended curettage, with or without adjuvant therapy, bone graft, or cement packing. Conversely, there is still considerable high recurrence rate even after extended curettage with cementing $(0-29 \%)$. As such, hip replacement surgery is a suitable treatment for patients with pathologic fracture and for those with an extensive lesion of the proximal femur. We report our experience of a young patient with a pathologic femoral neck fracture, secondary to GCTb of the proximal femur. A calcar replacing stem was utilized since the tumor and surgical resection involved the lesser trochanter.
\end{abstract}

Keywords: Calcar replacing; Giant cell tumor; Proximal femur; Total hip replacement

\section{Level of Evidence: Level IV, Case report}

\section{Case Report}

A 35 year old male truck driver had a 4 month history of intermittent, constricting pain of the right hip and groin area with a maximum VAS score of 6/10. The pain was present even at rest and

*Corresponding author: Juan Paulo Panti, Department of Orthopedic Surgery, University of the Philippines - Philippine General Hospital, Taft Ave, Manila, Philippines, Tel: +63 423314601; E-mail: docpaulopanti@gmail.com

Citation: Panti JP, Dimayuga C, Bernardo P (2015) Calcar-replacing Total Hip Replacement for A Giant Cell Tumor of the Proximal Femur: A Case Report and A Review of Literature. J Orthop Res Physiother 1: 012.

Received: May 21, 2015; Accepted: June 20, 2015; Published: August 20, 2015 was not exacerbated by physical activity nor position. He complained of walking with a limp, and difficulty in ambulation without support. The patient did not recall any history of fall nor previous trauma to the right hip. There were no other associated symptoms such as fever, weight loss, or presence of mass on the right hip. The patient sought initial consult with a general practitioner, and diagnostic work-up including plain radiographs of the hip were done. The results of the blood examination which included complete blood count, erythrocyte sedimentation rate, C-reactive protein, and alkaline phosphatase did not imply infection or malignancy. The plain radiographs of the hip showed a well-delineated osteolytic lesion in the proximal femur, from the femoral neck extending down to the area of the lesser trochanter. There was no cortical break noted on the plain X-ray films. The patient was prescribed analgesics for pain, advised non-weight bearing, and was given a referral to an orthopedic tumor specialist. However, the patient did not comply with the advised referral and follow up. He resumed his regular physical activities and was full weight bearing against medical advice.

Two weeks prior to surgery, the patient's pain increased in intensity up to a VAS score of 9/10. He did not recall any incident of fall or trauma. His limp worsened and was unable to put weight on his right lower extremity. He was eventually brought to our institution's out-patient clinic. After initial assessment from the clinic's triage, the patient was referred to our institution's orthopedic and musculoskeletal tumor service. Physical examination done both by the orthopedic-musculoskeletal tumor specialist and orthopedic resident, indicated leg length shortening of $0.5 \mathrm{~cm}$ on the right lower extremity, right hip tenderness upon palpation, and a positive heel pound test. No skin lesions, palpable mass, nor lymphadenopathy were noted. The modified Musculoskeletal Tumor Society rating functional (MSTS) score was 4/30. Repeat plain radiographs of the hip revealed a pathologic fracture of the right femoral neck at the area of the lesion (Figure 1). The proximal femoral lesion was characterized as epi-metaphyseal, osteolytic with well demarcated borders, with endosteal expansion, cortical break, and has soft tissue extension anteriorly; but without any matrix. The lesion extended from the femoral neck up to the base of the lesser trochanter. The patient was admitted for further work-up and his right lower extremity was placed in skin traction. Magnetic resonance imaging of the hip confirmed a well delineated homogenous $8 \times 7 \mathrm{~cm}$ lesion from the greater trochanter up to the level of the base of the lesser trochanter (Figure 2). A pre-operative tru-cut biopsy was done in the ward to exclude other differential diagnosis such as aneurysmal bone cyst and other primary bone tumor. The results confirmed giant cell tumor of the bone. The radiologic grade of the tumor was a Campanacci III due to the anterior cortical break and soft tissue extension, while the clinical and histologic grade was an Enneking 3 (for benign lesions). A pre-operative chest X-ray was done to rule out pulmonary metastasis, and showed negative results. The authors decided to pursue wide excision and perform total hip replacement due to the patient's age and function, high recurrence for GTCb, along with the extensiveness of the lesion and the cortical break. Prosthesis specifications that were considered included a custom-made proximal femur endoprosthesis or a proximal femoral allograft composite. However, due to financial constraints and unavailability of a proximal femur allograft, a 
calcar-replacing femoral stem was selected due to the involvement and possible excision of the calcar femorale and lesser trochanter.

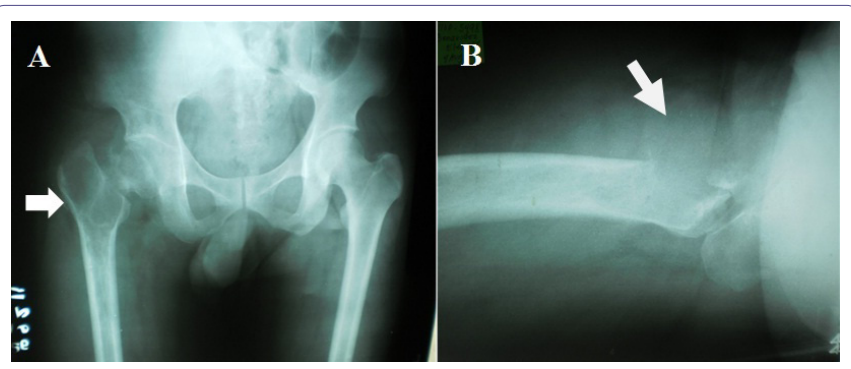

Figure 1: Plain radiographs of the hip revealing an osteolytic lesion with a pathologic fracture of the right femoral neck at the area of the lesion.

A) Arrow pointer showing proximal femoral lesion characterized as epi-metaphyseal, osteolytic with well demarcated borders, has endosteal expansion, cortical break, soft tissue extension, but without any matrix. The lesion extending from the femoral neck up to the lesser trochanter,

B) Arrow pointer showing cortical break at the anterior cortex of the greater trochanter and soft tissue extension of the tumor.

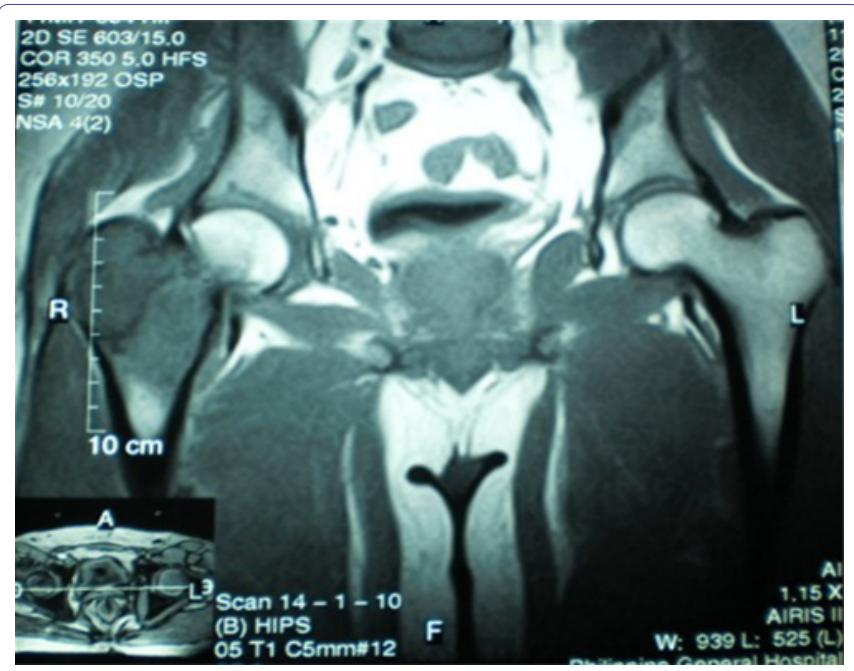

Figure 2: Magnetic resonance imaging coronal T1 image demonstrates a well delineated homogenous $8 \times 7 \mathrm{~cm}$ lesion from the greater trochanter up to the level of the base of the lesser trochanter.

\section{Surgical Technique}

The patient was placed on lateral decubitus position under general anaesthesia. A curvilinear longitudinal skin incision was made starting proximal to the greater trochanter and following a parallel course to the femoral shaft. After retraction of the subcutaneous tissue, careful dissection was carried out to perform a wide resection of the proximal femur lesion up to $1.5 \mathrm{~cm}$ distal to the base of the lesser trochanter including the insertion of iliopsoas, vastus lateralis, gluteus medius, short external rotators, and proximal portion of tensor fascia lata. The proximal femur lesion was separated distally from the shaft with the use of an oscillating saw, while the femoral head was dislocated from the acetabulum (Figure 3). An intralesional tissue sample was sent for frozen section to confirm diagnosis, while surrounding soft tissue samples were sent to check adequacy of resection margins. An uncemented press-fit grit-blasted titanium acetabular cup, coated with hydroxyapatite (Figure 4), was inserted along with titanium cancellous screws (United Orthopedic Corporation, Taiwan). This was mounted with an Ultra High Molecular Weight (UHMW) polyethylene acetabular liner fitted with a $\mathrm{BIOLOX}^{\mathrm{TM}}$ (United Orthopedic Corporation, Taiwan) ceramic head. For the femoral stem, a $160 \mathrm{~mm}$ long cobalt chrome GTF calcar-replacing femoral stem (United Orthopedic Corporation, Taiwan) was inserted with a $2^{\text {nd }}$ generation cementing technique. Excess cement was moulded around the junction between the femoral shaft and the calcar component of the implant (Figure 5). The gluteus medius and iliopsoas were attached to the hole on the proximal part of the femoral component using Ethibond Excel ${ }^{\mathrm{TM}}$ sutures. The vastus lateralis was sutured to the tensor fascia lata. A drain was positioned beneath the tensor fascia lata prior to skin closure. There was a leg lengthening of $0.5 \mathrm{~cm}$ of the operated limb on inspection, andan abduction pillow was placed between the patient's legs post-operatively. Prophylactic deep venous thrombosis management have been routinely administered. The patient was instructed touch-weight bearing for up to two weeks, and progressively improved to full weight bearing in 6 weeks post-op. The final histopathology report noted osteoclastic giant cells sporadically distributed throughout the stromal cells which confirmed the diagnosis of GCTb (Figure 6). The stromal cells were comprised of mononuclear round cells, instead of the spindle-shaped variant which is associated with the risk of malignant transformation [1]. His succeeding follow-up appointments at two weeks, first month, $3^{\text {rd }}$ month, and $6^{\text {th }}$ month post op were straightforward. His latest follow-up was at one year post-op, where the patient was ambulating full weight-bearing and without use of any assistive device. The patient walked without limp and only had a slight Trendelenberg sign on physical exam (Figure 7). The most recent radiographs showed no implant loosening, peri-prosthetic fracture, nor any evidence of tumor recurrence (Figure 8). A repeat chest radiograph noted no evidence of metastasis. The latest musculoskeletal tumor society rating functional score improved to $28 / 30$ on latest follow-up.
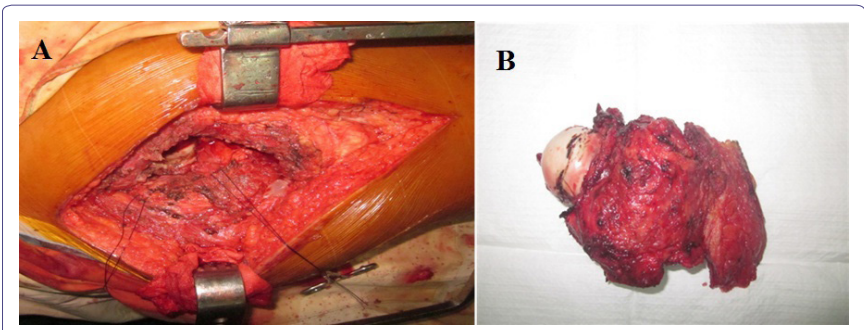

Figure 3: En-block resection of proximal femur up to $1.5 \mathrm{~cm}$ distal to the base of the lesser trochanter including insertion of iliopsoas, vastus lateralis, gluteus medius, short external rotators and proximal portion of tensor fascia lata.

\section{Discussion}

Aside from the scarcity of its location, selecting the appropriate surgical treatment for giant cell tumor of the proximal femur is still debatable [1-5]. Non-surgical management for consideration may include treatment with radiation therapy, embolization, and intralesional injections (steroid, interferon, calcitonin, and denosumab). Early history regarding the use of radiation for GCTb control was unsatisfactory, with local recurrence at $50-70 \%$ and the risk of radiation-induced malignant transformation was $7-25 \%$ [1]. Recent technological advances have improved outcomes, with reported oncologic control of $85-90 \%$ and risk of malignant transformation decreased to $0-8 \%$ [6-8]. Pre-operative trans-arterial embolization have been used in difficult to resect GCTB lesions of the spine and pelvis, where extensive blood loss would have been expected [9]. A handful of case reports in maxillofacial surgery have described the use of intralesional injections with either steroid 


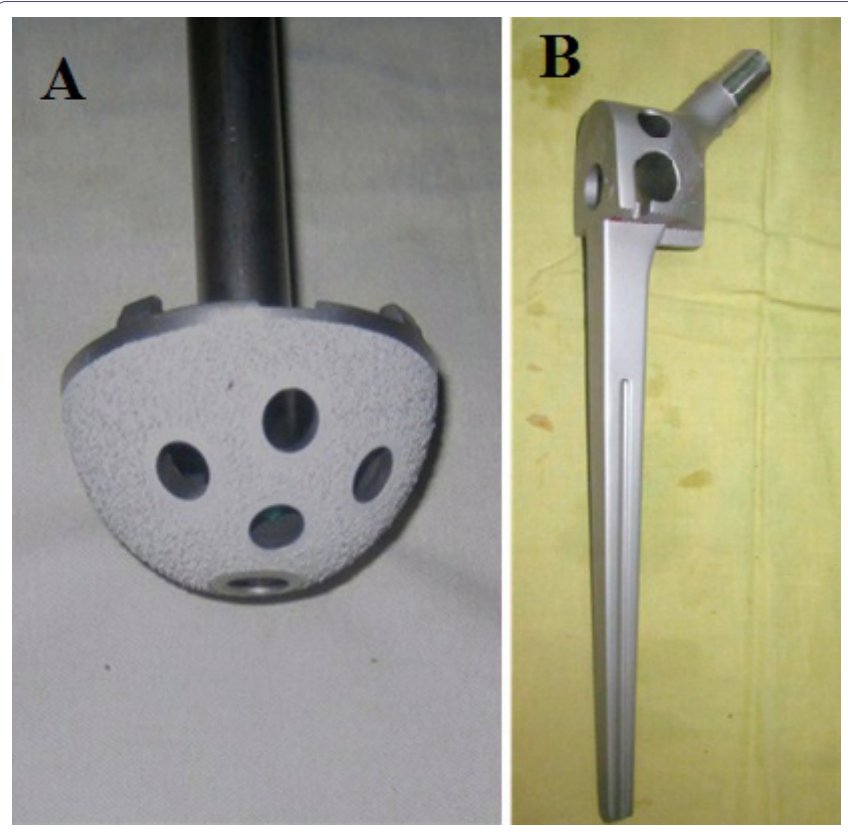

Figure 4: Total hip replacement implants used: A) An uncemented grit-blasted titanium acetabular cup, coated with hydroxyapatite, B) A $160 \mathrm{~mm}$ long cobalt chrome GTF calcar-replacing femoral stem.

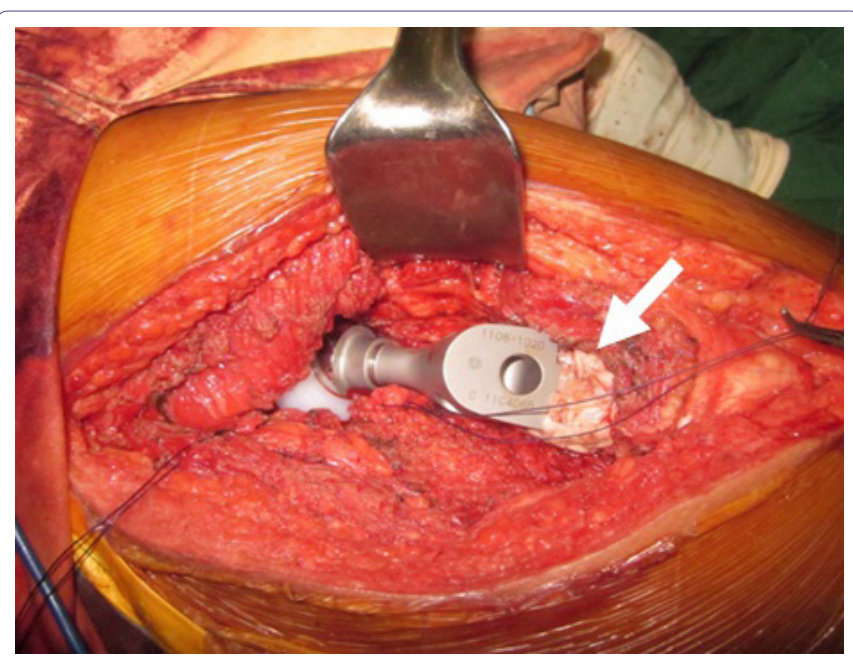

Figure 5: Arrow pointer showing excess cement that was moulded around the junction between the femoral shaft and the calcar component of the implant.

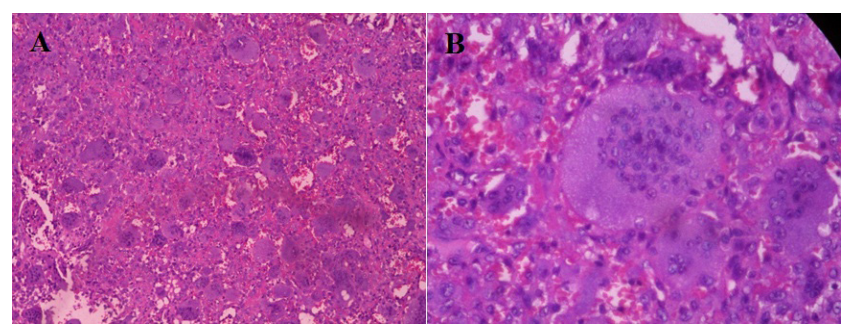

Figure 6: Histopathologic section showing osteoclastic giant cells, which are characterized with numerous nucleoli centrally located within the cytoplasm.

A) Low power magnification: hematoxylin-eosin, original magnification $\times 40$,

B) High power magnification: hematoxylin-eosin, original magnification $\times 100$

[10], interferon [11], calcitonin [12], bisphosphonates [13], or denosumab [14] for GCTb eradication. However, the results are

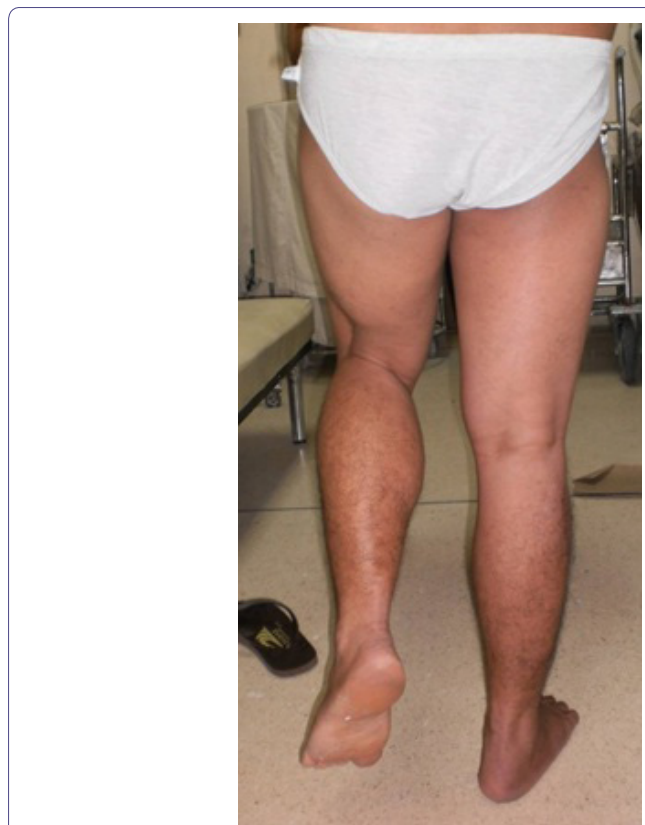

Figure 7: The patient walking without limp and demonstrated only had a sligh Trendelenberg sign on physical exam.

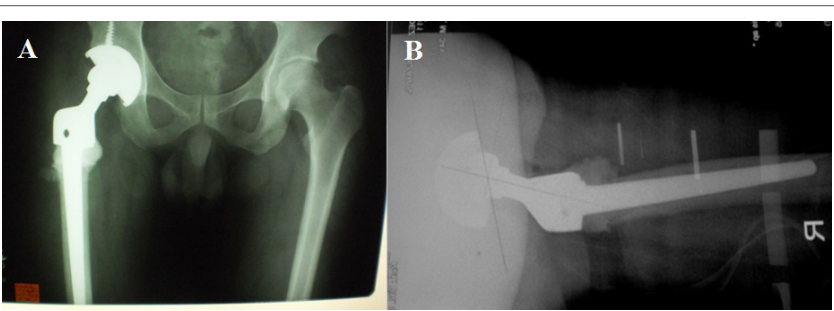

Figure 8: The most recent radiographs showed no implant loosening peri-prosthetic fracture, nor any evidence of tumor recurrence.

inconclusive and there is no evidence to support its use for a proximal femur lesion.

Joint salvaging surgery is primarily contemplated especially if the patient is relatively young, and the lesion is small and well contained [15-17]. This classically involves extended curettage, +/- adjuvant, and packing the defect either with bone graft or bone cement. Local recurrence rate after extended curettage however varies in literature, as it is $4.5-78 \%$ without cementing and $0-29 \%$ after cementing [18-20]. En-bloc resection of the lesion will certainly decrease, if not, eliminate the risk of tumor recurrence [21]. Additionally, it is presumed that there is no role for joint salvaging measures if the patient has a displaced pathologic fracture, or if the tumor is uncontained. In the contrary, Sim and Lang (1997) published a case report about a proximal femur GCTb with a transcervical fracture treated with internal fixation using a dynamic hip screw combined with valgus osteotomy, curettage, and bone grafting [17]. The latest follow-up was at 35 months, and the patient did not show any evidence of metastasis nor implant failure. However, at the latest follow-up there was a noted deformation of the femoral head that was absent prior to surgery. Furthermore, pre-operatively their patient did not have an extensive cortical break or soft-tissue extension unlike in our case. For our case, we opted for tumor resection and reconstruction due to the patient's pathologic fracture, cortical break, soft-tissue extension, better tumor control and the lesser incidence of recurrence. The 
Citation: Panti JP, Dimayuga C, Bernardo P (2015) Calcar-replacing Total Hip Replacement for A Giant Cell Tumor of the Proximal Femur: A Case Report and A Review of Literature. J Orthop Res Physiother 1: 012.

options for hip reconstruction after resection, includes excisional arthroplasty, hemi-arthroplasty or total hip replacement.

Hip joint reconstruction following excision is valuable for maintaining the stability and normalization of gait. However, there is always the risk of sacrificing vital tendinous insertions of hip abductors, adductors, flexors, and external rotators if the excision involves removing either the greater or the lesser trochanter. Furthermore, there is also the risk of taking out the dense vertically oriented calcar femorale at the posteromedial portion of the proximal femur, which support majority of the hip axial load. As with our with joint replacement in literature, there were only two patients who have had tumor recurrence. All studies reported improvement of latest functional outcome scores (Harris hip or MSTS score).

Comparable to data reported on literature, our patient had significant improvement in his MSTS score. Albeit the short term follow-up, it is important to note that the patient did not have any tumor recurrence or any mechanical signs of implant failure. It would be interesting to note the long term survivorship of this implant and follow-up the functional outcome of the patient in the future.

\begin{tabular}{|c|c|c|c|c|c|}
\hline Authors/ Year & No. of patients & Type of resection & Implant used & $\begin{array}{l}\text { Mean follow-up } \\
\text { (months) }\end{array}$ & Clinical outcome \\
\hline Kulkarni SS et al., [23] & 1 & Wide excision & Charnley type low-friction THA & 32 & $\begin{array}{l}\text { No tumor recurrence; Patient pain-free, full-weight } \\
\text { bearing, but with mild Trendelenburg lurch }\end{array}$ \\
\hline Sakayama K et al., [24] & 4 & Wide excision & $\begin{array}{l}\text { Two THA (Implant not } \\
\text { specified) and two bipolar } \\
\text { hemi-arthroplasty }\end{array}$ & 77.5 & $\begin{array}{l}\text { No tumor recurrence. The mean MSTS functional } \\
\text { score was } 93 \% \text {. }\end{array}$ \\
\hline Khan SA et al.,[25] & 12 & Wide excision & $\begin{array}{l}\text { Customized, bipolar, cemented } \\
\text { proximal femoral megapros- } \\
\text { thesis }\end{array}$ & 57 & $\begin{array}{l}\text { No tumor recurrence; No incidence of aseptic loosen- } \\
\text { ing or dislocation. The mean MSTS score is } 28.3 \text {. }\end{array}$ \\
\hline Nakano S et al., [26] & 1 & Wide excision & $\begin{array}{l}\text { Cemented custom-made } \\
\text { prosthesis }\end{array}$ & 384 (32 years) & $\begin{array}{l}\text { No tumor recurrence, and with signs of bone formation } \\
\text { at muscle re-attachment sites to the prosthesis. Mean } \\
\text { Harris hip score of } 100 .\end{array}$ \\
\hline Dhatt S et al., [27] & 1 & Wide excision & Custom made megaprosthesis & 36 & $\begin{array}{l}\text { No tumor recurrence nor any metastasis; no implant } \\
\text { loosening. The MSTS score is } 26.7 \text {. }\end{array}$ \\
\hline Malhotra R et al., [22] & 18 & Wide excision & $\begin{array}{l}\text { Uncemented Acetabular } \\
\text { cup; ceramic-on-ceramic } \\
\text { bearings; proximal femoral } \\
\text { allograft-prosthesis composite }\end{array}$ & 54 & $\begin{array}{l}\text { No tumor recurrence; Harris hip scores: } 13 \text { excellent } \\
\text { and } 5 \text { good outcomes. All allografts united. }\end{array}$ \\
\hline Wisbek AE et al., [28] & 14 & Wide excision & $\begin{array}{l}\text { Total hip replacement }(8 \mathrm{pxs}) \\
\text { hemi-arthroplasty }(1 \mathrm{px}), \text {, en- } \\
\text { doprosthetic joint replacement } \\
(5 \mathrm{pxs})\end{array}$ & 108.3 & $\begin{array}{l}\text { Mean MSTS scores for THR was } 25.7 \text { and endopros- } \\
\text { thesis was } 24.7 \text {. } \\
\text { Complications: Two patients treated with THR had } \\
\text { tumor recurrence; } 1 \text { THR and } 1 \text { endoprosthesis had } \\
\text { dislocation; } 1 \text { hemi-arthroplasty was revised to a THR } \\
\text { and } 1 \text { THR had an acetabular cup revision. }\end{array}$ \\
\hline
\end{tabular}

Table 1: A review of literature investigating the treatment of proximal femur GCT with excision and hip joint replacement.

patient, we expected to resect distal to the base of the lesser trochanter so we opted for a calcar-replacing long femoral stem. The aim is to have proximal portion of the femoral implant sitting on top of the femoral cortex, while the long stem provides stability and diaphyseal fixation. There are also designed holes on the proximal part of the femoral implant for re-attachment of the hip abductors and the iliopsoas (Figure 4B). Another option for hip reconstruction after excision of the proximal femur, would be an Allograft-prosthesis Composite (APC). Malhotra et al., reported a case series of 18 patients diagnosed with GCTb of the proximal femur treated with excision of the proximal femur, and APC using irradiated fresh-frozen allograft. With a mean follow-up of 54 months, all patients had complete graft union and excellent Harris hip scores in 13 patients [22]. We did consider using a proximal femoral allograft composite prior to the operation, however there was none available at our institution at that time. We also decided to do a cemented femoral fixation not only for stability, but also since the use PMMA bone cement seems to reduce tumor recurrence rate.

A review of literature investigating the treatment of proximal femur GCTb with excision and joint replacement was done (Table 1). The objectives of the literature search included analysis of the clinical outcomes, check for any tumor recurrence, and to determine any complications. The articles mostly were case report or case series, and there was heterogeneity with the type of implants used amongst the studies. All but one study stated no tumor recurrence on the latest follow-up. Out of the 51 patients with proximal femur GCTb treated

\section{Conclusion}

Giant Cell Tumor of the bone (GCTb) of the proximal femur is an uncommon location for the lesion, but it can certainly present as a surgical and treatment challenge. A calcar-replacing total hip replacement is a feasible surgical option for a proximal femur GCTb, especially if it is complicated by extensive cortical erosion and a pathologic fracture of the femoral neck.

\section{References}

1. Szendröi M (2004) Giant-cell tumor of bone. J Bone Joint Surg Br 86: 5-12.

2. Turcotte RE, Wunder JS, Isler MH, Bell RS, Schachar N, et al. (2002) Giant cell tumor of long bone: a Canadian Sarcoma Group study. Clin Orthop Relat Res 397: 248-258.

3. Campanacci M, Baldini N, Boriani S, Sudanese A (1987) Giant-cell tumor of bone. J Bone Joint Surg Am 69: 106-114.

4. Bloem JL, Reidsma II (2012) Bone and soft tissue tumors of hip and pelvis. Eur J Radiol 81: 3793-3801.

5. Mirra JM (1989) Giant Cell Tumors. In: Mirra JM (ed.). Bone Tumors, Clinical Radiologic and Pathologic correlations, Volume 2. Lea and Febiger, Philadelphia, USA. Pg no: 942.

6. Malone S, O'Sullivan B, Catton C, Bell R, Fornasier V, et al. (1995) Long-term follow-up of efficacy and safety of megavoltage radiotherapy in high-risk giant cell tumors of bone. Int J Radiat Oncol Biol Phys 33: 689-694.

7. Bell RS, Harwood AR, Goodman SB, Fornasier VL (1983) Supervoltage radiotherapy in the treatment of difficult giant cell tumors of bone. Clin Orthop Relat Res. Pg no: 208-216. 
8. Bennett CJ Jr, Marcus RB Jr, Million RR, Enneking WF (1993) Radiation therapy for giant cell tumor of bone. Int J Radiat Oncol Biol Phys 26: 299-304.

9. Zhou M, Yang H, Chen K, Wang G, Lu J, et al. (2013) Surgical treatment of giant cell tumors of the sacrum and spine combined with pre-operative transarterial embolization. Oncol Lett 6: 185-190.

10. El Hadidi YN, Ghanem AA, Helmy I (2015) Injection of steroids intralesional in central giant cell granuloma cases (giant cell tumor): Is it free of systemic complications or not? A case report. Int J Surg Case Rep 8: 166-170.

11. Kaban LB, Mulliken JB, Ezekowitz RA, Ebb D, Smith PS, et al. (1999) Antiangiogenic therapy of a recurrent giant cell tumor of the mandible with interferon alfa-2a. Pediatrics 103: 1145-1149.

12. de Lange J, van den Akker HP, van den Berg H, Richel DJ, Gortzak RA (2006) Limited regression of central giant cell granuloma by interferon alpha after failed calcitonin therapy: a report of 2 cases. Int $\mathrm{J}$ Oral Maxillofac Surg 35: $865-869$.

13. Tse LF, Wong KC, Kumta SM, Huang L, Chow TC, et al. (2008) Bisphosphonates reduce local recurrence in extremity giant cell tumor of bone: a case-control study. Bone 42: 68-73.

14. Mak IW, Evaniew N, Popovic S, Tozer R, Ghert M (2014) A translational study of the neoplastic cells of giant cell tumor of bone following neoadjuvant denosumab. J Bone Joint Surg Am 96: 127.

15. Schajowicz F (1981) Giant cell tumor (Osteoclastoma). In: Schajowicz F (ed.). Tumors and tumorlike lesions of bone and joints, Springer - Verlag, New York, USA. Pg no: 205-242.

16. Moon MS, Kim SS, Moon JL, Kim SS, Moon H (2013) Treating giant cell tumors with curettage, electrocautery, burring, phenol irrigation, and cementation. J Orthop Surg (Hong Kong) 21: 209-212.

17. Sim E, Lang S (1997) Joint salvaging surgery for an extensive giant cell tumor of the proximal femur complicated by a transcervical fracture. Arch Orthop Trauma Surg 116: 431-434

18. O'Donnell RJ, Springfield DS, Motwani HK, Ready JE, Gebhardt MC, et al (1994) Recurrence of giant-cell tumors of the long bones after curettage and packing with cement. J Bone Joint Surg Am 76: 1827-1833.
19. Komiya S, Inoue A (1993) Cementation in the treatment of giant cell tumor of bone. Arch Orthop Trauma Surg 112: 51-55.

20. Oda Y, Miura H, Tsuneyoshi M, Iwamoto $Y$ (1998) Giant cell tumor of bone: oncological and functional results of long-term follow-up. Jpn J Clin Oncol 28: 323-328.

21. Saikia KC, Bhattacharyya TD, Bhuyan SK, Bordoloi B, Durgia B, et al. (2011) Local recurrences after curettage and cementing in long bone giant cell tumor. Indian J Orthop 45: 168-173.

22. Malhotra R, Kiran Kumar GN, Digge VK, Kumar V (2014) The clinical and radiological evaluation of the use of an allograft-prosthesis composite in the treatment of proximal femoral giant cell tumors. Bone Joint J 96: 1106-1110.

23. Kulkarni SS, Dogra AS, Bhosale PB (1996) Total hip arthroplasty for giant cell tumor. J Postgrad Med 42: 82-84.

24. Sakayama K, Sugawara Y, Kidani T, Miyawaki J, Fujibuchi T, et al. (2007) Diagnostic and therapeutic problems of giant cell tumor in the proximal femur. Arch Orthop Trauma Surg 127: 867-872.

25. Khan SA, Kumar A, Inna P, Bakhshi S, Rastogi S (2009) Endoprosthetic replacement for giant cell tumor of the proximal femur. J Orthop Surg (Hong Kong) 17: 280-283.

26. Nakano S, Enishi T, Hasan MY, Hanaoka N, Kawasaki Y, et al. (2009) Arthroplasty using a custom-made cemented total hip prosthesis for an extensive giant cell tumor of the proximal femur: report of a patient followed up for over 30 years. Arch Orthop Trauma Surg 129: 1171-1175.

27. Dhatt S, Tahasildar N, Tripathy SK, Shashidhar BK, Tamuk T (2010) Excision and endoprosthesis implantation for proximal femur giant cell tumor. WebmedCentral ORTHOPAEDICS 1: WMC001236.

28. Wijsbek AE, Vazquez-Garcia BL, Grimer RJ, Carter SR, Abudu AA, et al (2014) Giant cell tumor of the proximal femur: Is joint-sparing management ever successful? Bone Joint J 96: 127-131. 